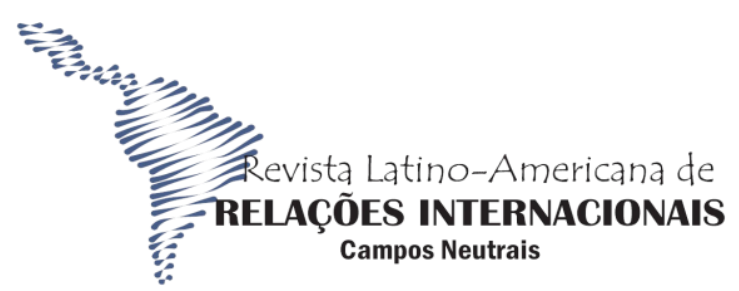

FURG

\title{
Os desafios socioambientais da construção de hidrelétricas na Amazônia: os casos dos municípios de Tucuruí e Altamira no estado do Pará
}

\author{
Maria Dolores Lima da Silva ${ }^{1}$ \\ Diego Brilhante Athayde ${ }^{2}$ \\ Jonas Guilherme Figueiredo da Trindade ${ }^{3}$ \\ João Elbio de Oliveira Aquino Sequeira ${ }^{4}$
}

Resumo: O objetivo desse artigo é verificar as características socioambientais que os municípios de Tucuruí e Altamira apresentam ao longo de três décadas, relacionando-as com a construção das hidrelétricas em seus territórios. A escolha desses dois munícipios se deu pelo fato de que a hidrelétrica de Tucuruí (UHT) e de Belo Monte (UHBM), em Altamira, foram construídas em contextos histórico-políticos diferentes, a UHT durante o regime militar e a UHBM em um contexto democrático. Usamos indicadores oficiais, do IBGE, IPEA, entre outros, para conduzir uma reflexão que questiona se o fato dessas duas hidrelétricas terem sido construídas em contextos diferentes faz diferença para a qualidade de vida da população desses municípios. Essa avaliação é guiada pela reflexão a respeito da concepção de desenvolvimento e do papel das políticas públicas na mitigação dos impactos da construção de hidrelétricas na Amazônia.

Palavras-Chave: hidrelétricas; desenvolvimento, qualidade de vida; Amazônia.

The socio-environmental challenges of the construction of hydroelectric plants in the Amazon: the cases of the municipalities of Tucuruí and Altamira in the state of Pará.

Abstract: The Objective of this article is to verify the socio-environmental characteristics that the municipalities of Tucuruí and Altamira have over three decades, relating them to the construction of hydroelectric plants in their territories. The choice of these two municipalities was due to the fact that the Tucuruí (UHT) and Belo Monte (UHBM) hydroelectric plants in Altamira were built in different historical-political contexts, the UHT during the military regime and the UHBM in a context democratic. We use official indicators, from IBGE, IPEA, among others, to conduct a reflection that questions whether the fact that these two hydroelectric plants were built in different contexts makes a difference to the quality of life of the population in these municipalities. This assessment is guided by

\footnotetext{
${ }^{1}$ Doutora em Ciência Política. Professora do Programa de Pós Graduação em Ciência Política e da Faculdade de Ciências Sociais da Universidade Federal do Pará.

${ }^{2}$ Mestrando em Ciência Política pela Universidade Federal do Pará.

${ }^{3}$ Mestrando em Ciência Política pela Universidade Federal do Pará.

${ }^{4}$ Advogado. Mestre em Ciência Política pela Universidade Federal do Pará e Doutor em Relações Internacionais pela Universidade de Brasília (UnB).
}

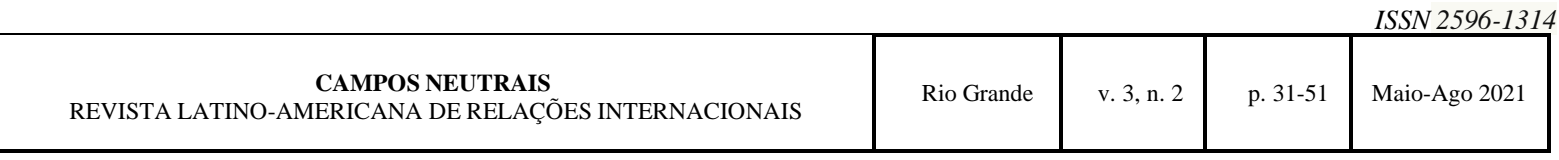


Os desafios socioambientais da construção de hidrelétricas na Amazônia: os casos dos municípios de Tucuruí e Altamira no estado do Pará

Dolores Silva et al.

reflection on the concept of development and the role of public policies in mitigating the impacts of the construction of hydroelectric plants in the Amazon.

Key words: hydroelectric; development, quality of life; Amazon

\section{Introdução}

O objetivo desse artigo é verificar as mudanças sociais e ambientais que os municípios de Tucuruí e Altamira sofreram com a construção de hidrelétricas em seus territórios. Ambos localizados no Estado do Pará, Tucuruí é banhado pelo rio Tocantins e Belo Monte pelo rio Xingu, na região amazônica. A construção desses dois grandes empreendimentos ocorreu em contextos políticos diversos, a hidrelétrica de Tucuruí foi construída no regime militar, e a hidrelétrica de Belo Monte foi construída em um contexto político democrático.

A discussão atual sobre políticas públicas de desenvolvimento regional nos apresenta sempre o problema das desigualdades entre as regiões e a necessidade de diminui-las. Os dados de desenvolvimento humano da região norte, comparado com as outras regiões do Brasil, mostram índices inferiores, daí a necessidade de implementação de políticas públicas que possam diminuir as assimetrias regionais. $\mathrm{O}$ discurso para justificar a construção de hidrelétricas na Amazônia pauta-se nessa premissa, ao apontar a geração de energia como insumo básico necessário à promoção do desenvolvimento econômico.

Essa concepção ainda é uma das principais bases de fundamentação da política nacional de desenvolvimento regional em 2019, que pauta suas ações tendo como objetivos: I) a redução das desigualdades regionais e II) a análise dos principais aspectos e causas das desigualdades. Seu diagnóstico serve à promoção de ações estatais onde a atração do interesse dos agentes de mercado para a região apesenta-se como a estratégia fundamental. Desenha-se uma concepção desenvolvimentista no sentido da redução das diferenças acentuadas entre regiões.

A necessidade de desenvolver a região Norte insere-se no projeto de inserção do Brasil na competição econômica internacional que remonta o governo de Getúlio Vargas. A função da Amazônia nesse processo seria de produzir energia para abastecer a industrialização brasileira nascente, inserindo a região na dinâmica do mercado internacional como fornecedora de insumos primários. 


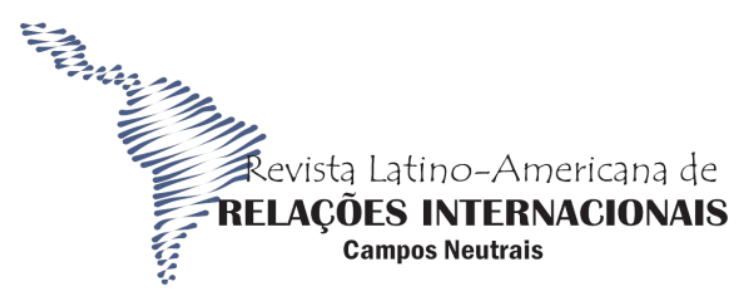

FURG

Vale destacar que, antes da Amazônia ser visualizada pela perspectiva moderna de desenvolvimento, essa região já estava inserida no capitalismo mundial, tendo seus bens naturais transformados em valores no mercado externo ${ }^{5}$. A história da exploração de recursos naturais da Amazônia em função do desenvolvimento econômico é mais antiga que a conceituação de desenvolvimento e, em sua forma mais conhecida, remonta a virada dos séculos XIX para o Século XX, com a extração do látex. Nessa época a exploração da borracha era a força motriz da economia regional ${ }^{6}$ e foi capaz de fazer com que elites locais, concentradas em Belém e Manaus, reproduzissem o estilo de vida europeu, momento conhecido como Belle époque amazônico ${ }^{7}$.

A análise dos impactos sociais e ambientais que a construção de hidrelétricas desencadeou nos territórios de Tucuruí e Altamira compreende um recorte temporal de 1991 a 2017. Adotamos uma estratégia metodológica de estudo de casos, onde comparamos municípios que localizam-se na Amazônia legal brasileira. Nosso objetivo é analisar indicadores dos municípios de Tucuruí e Altamira, com o intuito de verificar se os mesmos corroboram com a concepção desenvolvimentista de promoção de bem estar social para a população da região.

O artigo é divido em quatro tópicos, incluindo esta introdução. No segundo tópico, apresentamos alguns aspectos do conceito de desenvolvimento, concepção que conseguiu obter o apoio de diversos setores da sociedade para que o Estado praticasse ações visando inserir a Amazônia na economia de mercado. Destacamos como alguns autores interpretam a instalação desses projetos, e chamamos a atenção para as diferenças do contexto político

\footnotetext{
${ }^{5}$ Não iremos tratar do período de início da colonização regional, quando sociedades indígenas foram dizimadas e também incorporadas nas atividades de coleta das "drogas do sertão", que tinham grande importância para a economia dos colonizadores.

${ }^{6}$ Esse ciclo da borracha, que começou a declinar em 1912, passou por tentativa de retomada em meados dos anos 40, quando o mercado de borracha asiático foi fechado durante a segunda guerra mundial e a Amazônia voltou a ser a principal produtora desse produto

${ }^{7}$ Financiada pelo látex, a Belle Époque amazônica iniciou-se em 1871. Centrada principalmente nas cidades de Belém (capital do estado do Pará) [3] e Manaus (capital do estado do Amazonas) — chamadas de Paris dos Trópicos ou Paris n'América — período foi marcado por intensiva modernização de ambas as cidades no século XIX, com avanços arquitetônicos em relação a outras capitais brasileiras.
}

\begin{tabular}{|c|c|c|c|c|}
\hline $\begin{array}{l}\text { CAMPOS NEUTRAIS } \\
\text { REVISTA LATINO-AMERICANA DE RELAÇÕES INTERNACIONAIS }\end{array}$ & Rio Grande & v. 3, n. 2 & p. $31-51$ & Maio-Ago 2021 \\
\hline
\end{tabular}


Os desafios socioambientais da construção de hidrelétricas na Amazônia: os casos dos municípios de Tucuruí e Altamira no estado do Pará

Dolores Silva et al.

institucional em que ocorreram as decisões sobre as usinas hidrelétricas de Tucuruí e Belo Monte.

No terceiro tópico focamos nos dois contextos locais, apresentando indicadores econômicos, sociais e ambientais dos municípios de Tucuruí e Altamira, que abrigam as duas grandes usinas hidrelétricas paraenses. Subdividimos essa seção em vários tópicos para simplificar a apresentação dos dados. Nosso objetivo é verificar as mudanças socioambientais que esses municípios sofreram, levando em consideração se a perspectiva desenvolvimentista e os planos baseados nessa concepção estão de fato produzindo modificações positivas na vida da população.

Esses indicadores socioambientais fazem referência ao contexto urbano da região, visto que os impactos sobre a natureza e os ecossistemas amazônicos exigem dados mais complexos que são bastante abordados pelos especialistas. Por último concluímos o trabalho refletindo sobre o dilema dos projetos de desenvolvimento na Amazônia que sustentam a produção de riquezas para o país, mas não alcançam de forma satisfatória a vida da população local.

\section{A produção de energia no contexto de projetos de desenvolvimento na Amazônia}

Associada a uma preocupação com a soberania nacional, o Estado brasileiro impulsionou a implementação de projetos de desenvolvimento econômico na Amazônia durante os governos de ditadura militar (1964-1985), onde uma das suas ações estratégicas básicas foi o uso dos recursos hídricos da região na produção de energia. Os grandes projetos energéticos foram planejados com o objetivo de fomentar a economia, integrando a exploração de recursos naturais ao dinamismo da produção capitalista. Com dimensão territorial de proporções continentais e abundante quantidade de bens naturais, os projetos de desenvolvimento desencadearam grandes impactos sociais e ambientais, derivados da construção de infraestrutura para servir aos empreendimentos econômicos, assim como da exploração de produtos primários como os minérios, a madeira e os recursos hídricos.

As ideias desenvolvimentistas no Brasil se propagaram a partir da chamada era Vargas, se estendendo ao período do governo de Juscelino Kubitschek, no período democrático de 1945 a 1964. Tal perspectiva foi marcada pelo fomento da industrialização nacional, com a produção de bens de consumo, abertura ao capital externo e por construções no setor de transporte - rodovias, aeroportos e portos. Foi nesse contexto que o foco de desenvolvimento se voltou para a obtenção massiva de bens naturais abundantes no Brasil, 


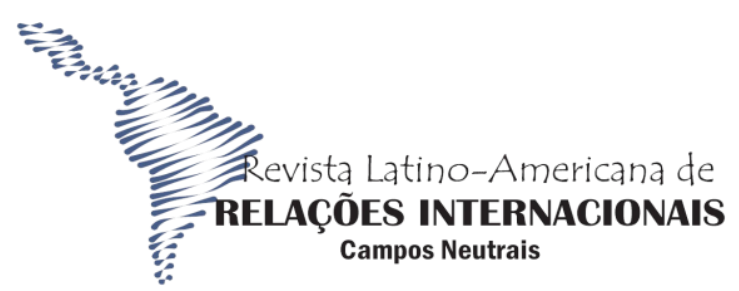

FURG

como o minério e a produção de energia elétrica através da implementação de usinas hidrelétricas (LIRA, 2005).

As estratégias de desenvolvimento no Brasil estão relacionadas com estudos realizados na década de 50, especialmente no âmbito da $\mathrm{CEPAL}^{8}$, com o intuito de diagnosticar e apresentar propostas para inserir os países mais pobres na dinâmica capitalista global. Em um contexto em que a segunda guerra mundial tinha devastado a economia dos países ricos, essa inserção ajudaria estes países a reerguerem seu dinamismo econômico. Os estudos sobre a estrutura sócio econômica dos países latino americanos fizeram grandes contribuições aos projetos de intervenção política nas sociedades, então qualificadas como de terceiro mundo, visto que buscaram compreender as especificidades do subdesenvolvimento e como superá-lo.

A teoria de polos de desenvolvimento fundamentou o planejamento do, sendo a construção das hidrelétricas um elemento central dos Programas implementados na Amazônia (CASTRO, 2018). Na condição de área periférica do capitalismo, haveria a necessidade de ações do Estado que impulsionasse seu desenvolvimento. Peter Evans (1992) interpretou a questão do desenvolvimentismo na década de 50 e 60 como a necessidade de os aparelhos de Estado serem usados para promoverem mudanças estruturais, acelerando a industrialização, modernizando a agricultura e fornecendo a infraestrutura necessária à urbanização. Nesse contexto de crescimento industrial e populacional tornou-se imprescindível a produção de energia elétrica como instrumento basilar de industrialização.

O elemento essencial do conceito de desenvolvimentismo desse contexto é a ligação entre produção de bens de consumo e o aumento do $\mathrm{PIB}^{9}$, contudo isso sentido vem mudando ao longo do tempo ao se considerarem indicadores a respeito do bem estar da população (PRATES et al., 2017). A respeito do desenvolvimentismo no Brasil e na América Latina,

\footnotetext{
${ }^{8}$ A Comissão Econômica para a América Latina e Caribe (CEPAL) foi criada em 1948 pela ONU.

${ }^{9}$ A promoção do desenvolvimento econômico no Brasil durante os governos militares tinha como mote a ideia de "crescer o bolo para depois dividi-lo", ou seja, uma concepção em que o desenvolvimento da economia levaria ao bem estar social como consequência.
}

\begin{tabular}{|c|c|c|c|c|}
\hline \multicolumn{1}{|c|}{ ISSN 2596-1314 } \\
\begin{tabular}{|c|c|c|c} 
CAMPOS NEUTRAIS \\
REVISTA LATINO-AMERICANA DE RELAÇÕES INTERNACIONAIS
\end{tabular} & Rio Grande & v. 3, n. 2 & p. 31-51 & Maio-Ago 2021 \\
\hline
\end{tabular}


Os desafios socioambientais da construção de hidrelétricas na Amazônia: os casos dos municípios de Tucuruí e Altamira no estado do Pará

Dolores Silva et al.

Draibe e Riesco (2011) observam que a experiência desenvolvimentista latino americana foi marcada pelo conceito moderno de bem estar social, compreendendo a necessidade de desenvolver a economia ao mesmo tempo em que o Estado incorporou a adoção de políticas socais.

Contudo, na configuração do "Estado Latino Americano Desenvolvimentista de Bem Estar (ELADBE)" (Idem), ainda não estavam plenamente estabelecidos princípios e normas de proteção ao meio ambiente, que se globalizam a partir do final da década de 1980 (SILVA; CABRAL, 2018). Neste contexto de globalização novos atores sociais, como as ONGs e os atores judiciais, ocupam os espaços institucionais de participação e questionam as entranhas dos projetos de desenvolvimento que atingem de forma negativa populações locais (SEQUEIRA; SILVA, 2015; SILVA; ROSA, 2013).

A hidrelétrica de Tucuruí (UHT) foi uma das obras projetada e construída durante os governos militares, localizada no sudeste do estado do Pará na bacia do rio Tocantins, distante $300 \mathrm{~km}$ da capital Belém. Seu projeto foi pensado com o objetivo de abastecer de energia a indústria do alumínio e sua construção foi concluída no governo do general João Figueiredo (1979-1985), sendo instalada em 1984. O custo estimado desse empreendimento era de 2,5 bilhões de dólares, mas esse valor duplicou em encargos aos cofres públicos. Segundo Pinto (2012) essa obra teve como consequências a migração desordenada de trabalhadores de outras regiões do Brasil para o município de Tucuruí e o surgimento de movimentos populares que reivindicam, até o período atual ${ }^{10}$, direitos que não foram respeitados durante a construção.

Para Pereira (2014), os impactos negativos da UHT poderiam ter sido mitigados se tivesse existido a participação de setores sociais no processo decisório sobre esse empreendimento, como ocorreu no caso da usina hidrelétrica de Belo Monte (UHBM). Projetada ainda no regime militar, este projeto de infraestrutura se desenvolveu em contexto político democrático e começou a funcionar em 2016.

No março legal instaurado com a democracia de 1988 a decisão sobre a construção de hidrelétricas deve passar por diferentes instâncias institucionais antes de iniciar a obra. $\mathrm{Na}$ primeira, denominada de fase do setor elétrico, são tratadas as variáveis técnicas de engenharia e as questões ligadas ao planejamento e produção do empreendimento.

\footnotetext{
10 “Índios Assurini relatam à Justiça 40 anos de danos gerados pela Usina de Tucuruí (PA)" https://www.ecodebate.com.br/2018/05/07
} 


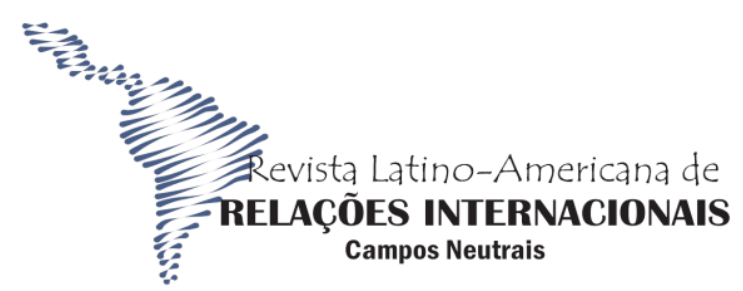

FURG

A segunda é a fase legislativa, cuja arena de discussão é o Congresso Nacional, quando os legisladores consideram os custos e os interesses dos grupos sociais que irão ser beneficiados ou afetados pelo projeto, tais como os grupos econômicos, as sociedades indígenas e quilombolas. Na terceira fase, dedicada ao setor ambiental, o IBAMA debate com os órgãos ambientais locais, Ministério Público, ONG's e representantes de grupos sociais das regiões afetadas, a respeito das ações que serão adotadas, com o intuito de mitigar danos decorrentes do empreendimento.

A UHBM é localizada na bacia do rio Xingu, no município de Altamira (PA) e foi inaugurada oficialmente em 2019. Nas fases do processo decisório sobre sua construção foi possível a adequação do projeto e a adoção de medidas compensatórias à população do entorno da obra.

Castro (2018) observa que o debate sobre os problemas socioambientais gerados pela construção de hidrelétricas se iniciou ainda na década de 70 do século $\mathrm{XX}$, devido ao fato dessas questões começarem a afetar a própria produtividade desses empreendimentos, sendo parte da cadeia de procedimentos para a produção de energia no contexto institucional democrático. Em sua concepção são os interesses em otimizar ganhos econômicos dos empreendimentos que movem as mudanças nos procedimentos prévios à construção de hidrelétricas, mais do que interesses na democratização do processo de decisão sobre políticas públicas.

A despeito da maior interação das instituições públicas com os atores sociais durante os processos que antecedem a instalação de hidrelétricas na Amazônia, as mesmas continuam a serem questionadas por movimentos sociais, populações indígenas e ribeirinhas, em função da modificação nas condições de sobrevivência dos grupos sociais locais.

O propósito deste trabalho não é entrar no debate sobre as intenções e efetividade da participação social no processo decisório de construção de hidrelétricas. Nosso objetivo é evidenciar algumas dimensões da condição de vida dos habitantes do entorno dessas grandes 
Os desafios socioambientais da construção de hidrelétricas na Amazônia: os casos dos municípios de Tucuruí e Altamira no estado do Pará

Dolores Silva et al.

obras que determinam o descontentamento dessa diversificada população. Iremos comparar variáveis socioeconômicas e ambientais dos municípios de Tucuruí e Altamira, no estado do Pará, para refletir a respeito dos custos sociais e ambientais da implementação dessas usinas hidrelétricas.

As mudanças na compreensão acerca do desenvolvimento, com a consideração da existência de redes de proteção social mínima e de princípios de sustentabilidade ambiental, dão relevância a configuração das condições de vida das pessoas que vivem no entorna dessas duas grandes hidrelétricas. A distância no tempo entre a instalação dos dois projetos iluminam essa reflexão, na medida em que nos permitem considerar o que foi realizado e o que ainda carece de resposta aos impactos socioambientais na vida da população.

\section{A Construção das Hidrelétricas na Amazônia e seus impactos: os casos de Tucuruí e}

\section{Altamira}

No período democrático de 1946-1964 foi criado um plano de desenvolvimento para a Amazônia e uma instituição para implementá-lo, a Superintendência do Plano de Valorização Econômica da Amazônia - SPVEA. Órgão criado pela Lei no 1.806 , de 06 de janeiro de 1953, a SPVEA foi subordinada à Presidência da República e tinha como funções elaborar um Plano quinquenal, a ser apresentado ao Congresso Nacional, e controlar sua execução, coordenando as atividades e a distribuição de verbas para os órgãos que atuassem nos estados da região norte do Brasil. Nas diretrizes sobre o seu papel estava previsto investimento do governo federal em transporte e energia, onde se incluía estudo para a viabilidade de construção de novas hidroelétricas (FERREIRA; BASTOS, 2016; CARDOSO; MÜLLER, 2008).

Mas foi só na década 70 que o projeto da usina hidrelétrica de Tucuruí foi implementada e começou a operar na década de 80 sem mobilizar questionamentos tão salientes sobre seus impactos sociais e ambientais, como ocorreu no caso do processo de criação da hidrelétrica de Belo Monte. Entre os impactos locais de caráter social temos a precarização de serviços públicos, como saúde, segurança e educação, devido ao intenso e abrupto crescimento demográfico. Esses dois projetos são os maiores e mais rentáveis empreendimentos governamentais de energia elétrica instalados na região norte do Brasil, para alimentar o dinamismo econômico do país.

Enquanto vigorava a ditadura militar, não se pensava com tanta saliência na questão do meio ambiente no Brasil e as reivindicações sociais não eram bem recepcionadas pelo 


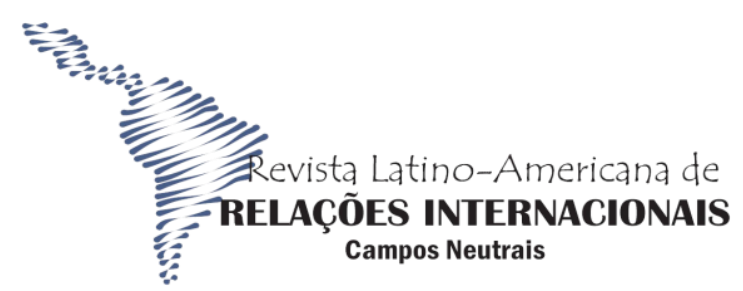

FURG

regime, sobretudo se elas conflitavam com o projeto de desenvolvimento que atendia aos anseios das elites econômicas do país (SILVA; CABRAL, 2018; ALONSO, 2007). Contudo, os grandes projetos de desenvolvimento contribuíram para aumentar as disparidades econômicas da região, a violência rural e urbana e a violação dos territórios indígenas e outras comunidades tradicionais. Conforme Serra e Fernández (2004, p.117):

\footnotetext{
"Na verdade, vários fatores concorreram para o desmatamento em larga escala sofrido pela região amazônica: a construção das grandes rodovias e das estradas vicinais; a criação de gado; a exploração de madeira; a colonização oficial e "espontânea"; a mineração e os projetos infraestruturais associados (estrada de ferro, hidrelétrica, etc.); e a fundição de ferro gusa. Todos esses empreendimentos, estimulados pelo governo brasileiro, estão inter-relacionados e contribuíram consideravelmente para agravar o desmatamento e a degradação ambiental na região.”
}

Nesse contexto, a insatisfação com a instalação da hidrelétrica em Tucuruí ficou sob o constrangimento do autoritarismo, diferenciando-se da hidrelétrica de Belo Monte em Altamira, que começou a ser parcialmente operada em 2016 sob intensa polemica e tentativas de obstrução através da ação de movimentos sociais e do Ministério Público. Conforme Pereira (2014, pp.161-185) o contexto de pluralismo político pós Constituição de 1988 influenciou a capacidade estatal no sentido de melhorar os padrões técnicos do projeto da hidrelétrica de Belo Monte, que foi construída com base em vários estudos de redução de impactos socioambientais.

Apesar da diferença nas trajetórias dessas duas UHs, a região de Altamira também sofre com as diversas alterações socioambientais em seu território. Podemos refletir sobre os impactos da construção das hidrelétricas na Amazônia verificando alguns registros que caracterizam os municípios de Tucuruí e Altamira, apresentados nas próximas seções.

\subsection{A renda per capita e postos de trabalhos nos municípios}

Os dados sobre a renda per capita apresentam crescimento de 1991 a 2017, com diferença pequena entre os municípios, entretanto, em 2017 a renda média dos dois

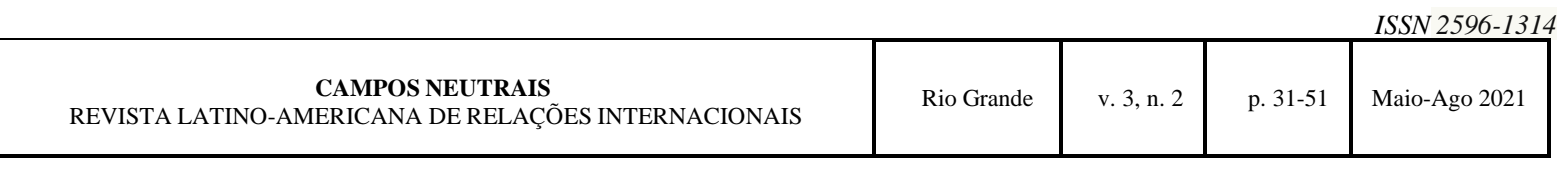


Os desafios socioambientais da construção de hidrelétricas na Amazônia: os casos dos municípios de Tucuruí e Altamira no estado do Pará

Dolores Silva et al.

munícipios se igualou. Entre os 5570 municípios brasileiros, Altamira está na $1763^{\mathrm{a}}$ posição em 2017 e Tucuruí na $2885^{\text {a }}$ renda média brasileira.

Tabela 1. Renda média per capita dos municípios de Tucuruí e Altamira

\begin{tabular}{lll}
\hline Ano & Tucuruí & Altamira \\
\hline $\mathbf{1 9 9 9}$ & $\mathrm{R} \$ 257,52$ & $\mathrm{R} \$ 276,44$ \\
$\mathbf{2 0 0 0}$ & $\mathrm{R} \$ 354,61$ & $\mathrm{R} \$ 401,93$ \\
$\mathbf{2 0 1 0}$ & $\mathrm{R} \$ 534,02$ & $\mathrm{R} \$ 492,05$ \\
$\mathbf{2 0 1 7}$ & $\mathrm{R} \$ 1.874,00$ & $\mathrm{R} \$ 1.874,00$ \\
\hline
\end{tabular}

Fonte: IBGE (produção dos próprios autores).

Quanto ao trabalho formal e renda, o salário médio da população nos dois municípios, segundo os dados do IBGE para o ano de 2017 apresentava a mesma média, equivalente a 2,5 salários, entretanto a taxa de pessoas com emprego formal tem uma diferença de 6 pontos percentuais entre os municípios. Chama atenção o rendimento das pessoas com uma ocupação que ganham até 1/2 salário mínimo, que para Altamira é de 41,5\% e para Tucuruí é de $41,6 \%$.

Tabela 2. Trabalho e renda dos municípios no ano de 2017

\begin{tabular}{cccc}
\hline Municípios & Salário médio formal & $\begin{array}{c}\text { População com } \\
\text { emprego formal }\end{array}$ & $\begin{array}{c}\text { População com } \\
\text { rendimento de até } \mathbf{1} \text { 2 } \\
\text { salário mínimo }\end{array}$ \\
\hline Altamira & 2,5 & $17,1 \%$ & $41,5 \%$ \\
Tucuruí & 2,5 & $11,8 \%$ & $41,6 \%$ \\
\hline
\end{tabular}

Fonte: IBGE (produção dos próprios autores).

Deve-se observar a semelhança da renda e do salário médios da população dos dois municípios, o que recomenda atentarmos para a existência de outras atividades produtivas nessas regiões, como agropecuária, por exemplo, que exerce um impacto importante na vida econômica desses municípios. Apesar da antecedência no tempo da construção da UHT não vemos um impacto econômico positivo no padrão econômico do município de Tucuruí que o diferencie da Altamira. Ambos são municípios com rendimentos muitos baixos, com quase metade da população ganhando meio salário mínimo.

\subsection{As taxas de criminalidade e homicídios nos municípios}

Nos gráficos abaixo apresentamos a taxa de homicídios, com dados a partir de 1996 e que se estendem até 2016. Esses índices foram calculados a partir do número de mortes 


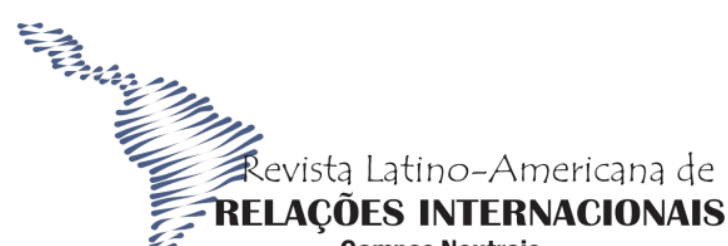

Campos Neutrais

FURG

violentas multiplicado por cem mil habitantes e dividido pela quantidade de habitantes da localidade.

Podemos observar no primeiro intervalo de 10 anos, que os índices de homicídios em Tucuruí são maiores do que em Altamira no mesmo período. Sendo que o processo de construção da Hidrelétrica de Tucuruí se iniciou no ano de 1971, a sua operacionalização iniciou em 1984 e houve uma revisão de sua capacidade em 2010.

\section{Gráfico 1.0}

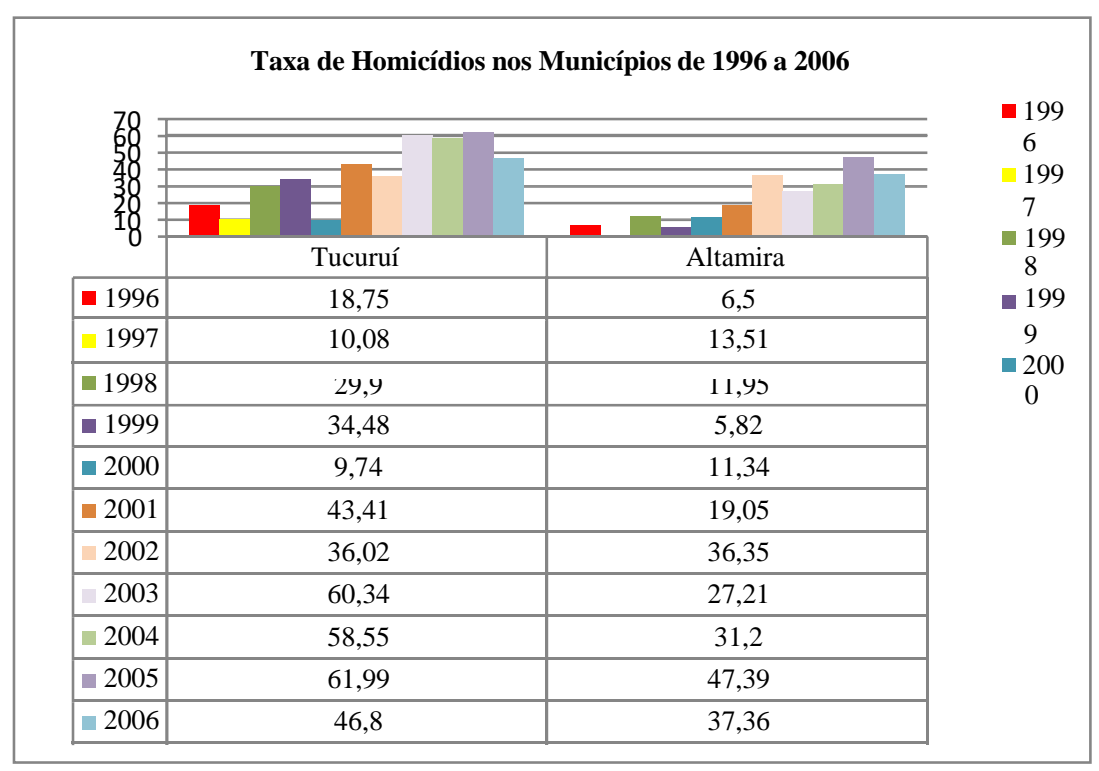

Fonte: Atlas da Violência 2020 (extraído pelos autores)..

No segundo gráfico, com dados do período de 2007 a 2016, podemos perceber os índices de mortes violentas em Tucuruí são maiores até 2009, em 2010, Altamira apresenta uma taxa parelha de mortes violentas com a taxa de Tucuruí, e a partir de 2011 o cenário se inverte de forma que Altamira passa a ter índices de mortes violentas maiores que as de 
Os desafios socioambientais da construção de hidrelétricas na Amazônia: os casos dos municípios de Tucuruí e Altamira

Tucuruí. Isto ocorre simultaneamente o fato de que o projeto da hidrelétrica de Belo Monte começa a ser posto em pratica.

\section{Gráfico 2.0}

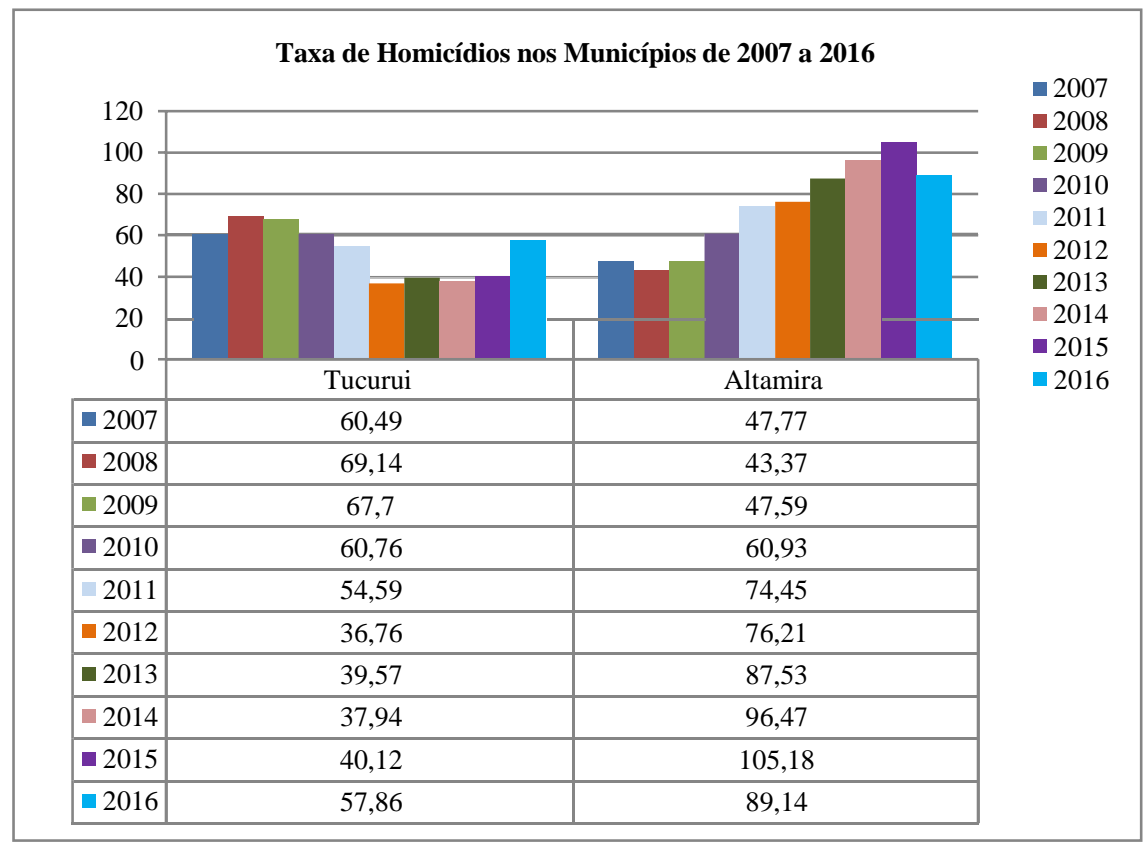

Fonte: Atlas da Violência 2020 (extraído pelos autores)..

Os dados da tabela 4, abaixo, mostram informações do estudo do Instituto de Pesquisa Econômica Aplicada (IPEA), realizado em parceria com o Fórum Brasileiro de Segurança Pública (FBSP), o “Atlas da Violência 2019”, que apresenta indicadores do ano de 2017. Os dados estatísticos mostram que Altamira e Tucuruí configuram dentro do Ranking de mais violentos do Brasil ultrapassando até mesmo a capital Belém, que tem população que se aproxima de um milhão e meio de habitantes.

Tabela 3: Índices de Homicídios em Municípios paraenses no ano de 2017

\begin{tabular}{lllll}
\hline Município & População & Registros & Hom. Ocultos & Taxa estimada \\
\hline Altamira & 111.435 & 149 & 0 & 133,7 \\
Marituba & 127.858 & 128 & 0 & 100,1 \\
Marabá & 271.594 & 239 & 3 & 89,0 \\
Ananindeua & 516.057 & 451 & 4 & 88,1 \\
Tucuruí & 110.516 & 80 & 6 & 77,5 \\
Belém & $1.452,275$ & 1.072 & 8 & 74,3 \\
\hline
\end{tabular}




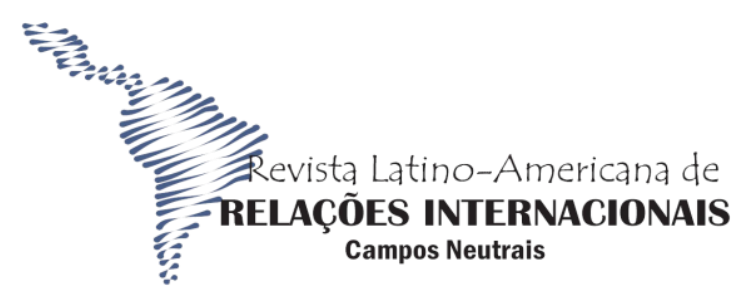

FURG

Fonte: IPEA, 2019

Os municípios sede dos grandes empreendimentos energéticos tiveram aumento alarmante da violência, Tucuruí registra 86 homicídios em 2017 e Altamira alcançou a marca de 149 homicídios registrados, se configurando como o munícipio mais violento do Pará.

Não podemos de imediato derivar da operabilidade das hidrelétricas o aumento da criminalidade, pois necessitamos de estudos mais robustos que correlacionem aumento da população, baixo nível de emprego e renda, acentuação da desigualdade social, entre outras variáveis, para chegar a esse tipo de conclusão. Porém é intuitiva a percepção das consequências de intensa mobilidade humana e de atividades econômicas mais dinâmicas em localidades cujas estruturas sociais e espaciais são complexas, como no caso do município de Altamira, no sudoeste do Pará, que é o maior do Brasil em extensão geográfica.

\subsection{A escolaridade da população dos municípios}

Quanto ao índice de escolaridade de cada município usaremos os dados o Atlas Brasil de 2013 que já mostram um perfil da evolução da educação nesses municípios. Os dados trabalhados consideram as unidades de observação que compõem do Índice de Desenvolvimento Humano (IDH), de onde se identificam as categorias de indivíduos que possuem o ensino fundamental completo/incompleto; médio completo e incompleto e superior completo e incompleto, Cada uma dessas características foram observadas em anos que separam um intervalo de dez anos. 
Os desafios socioambientais da construção de hidrelétricas na Amazônia: os casos dos municípios de Tucuruí e Altamira

\section{Gráfico 3.0}

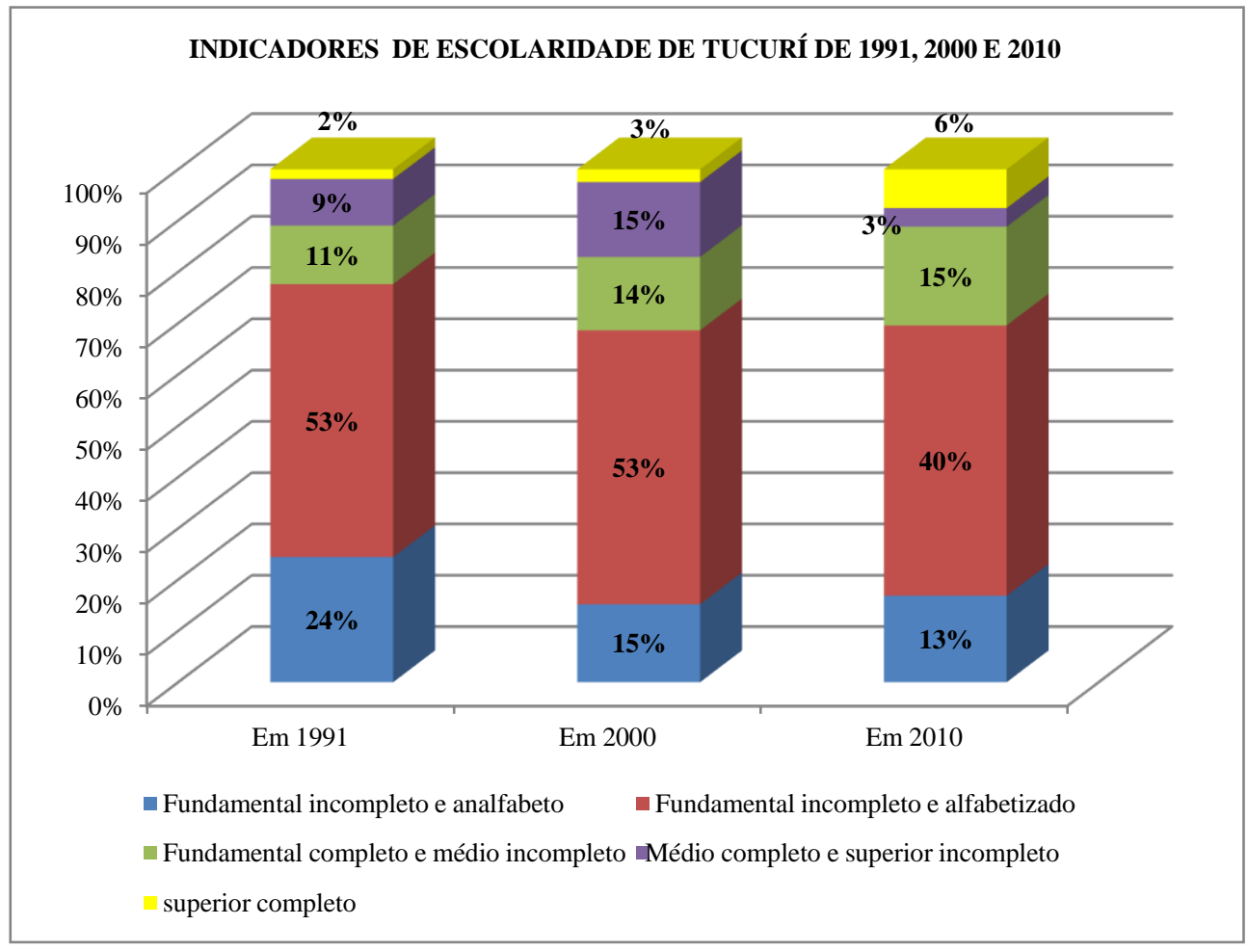

Fonte: do Atlas Brasil 2013 (extraído pelos autores).

Segundo os indicadores escolares de Tucuruí, podemos observar que as taxas de pessoas com ensino fundamental incompleto e analfabetas apresentam uma tendência de queda do período de 1991 a 2000, com uma diferença de 9\%. A partir do ano 2000 essa diminuição diminui para apenas $2 \%$ em comparação com o índice de 2010.

Já a escolaridade de nível superior, que no ano de 1991 é de apenas $1 \%$ da população de Tucuruí, em 2000 sobe para $2 \%$ e em 2010 sobe para 6\%. Mas, deve-se destacar que a maior faixa é de pessoas com ensino fundamental incompleto e analfabetos, que é de $40 \%$ em 2010, com queda de apenas 7.0 pontos em um intervalo de 20 anos. 


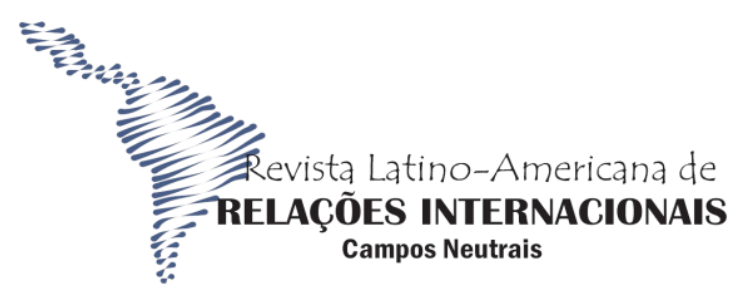

FURG

\section{Gráfico 4.0}

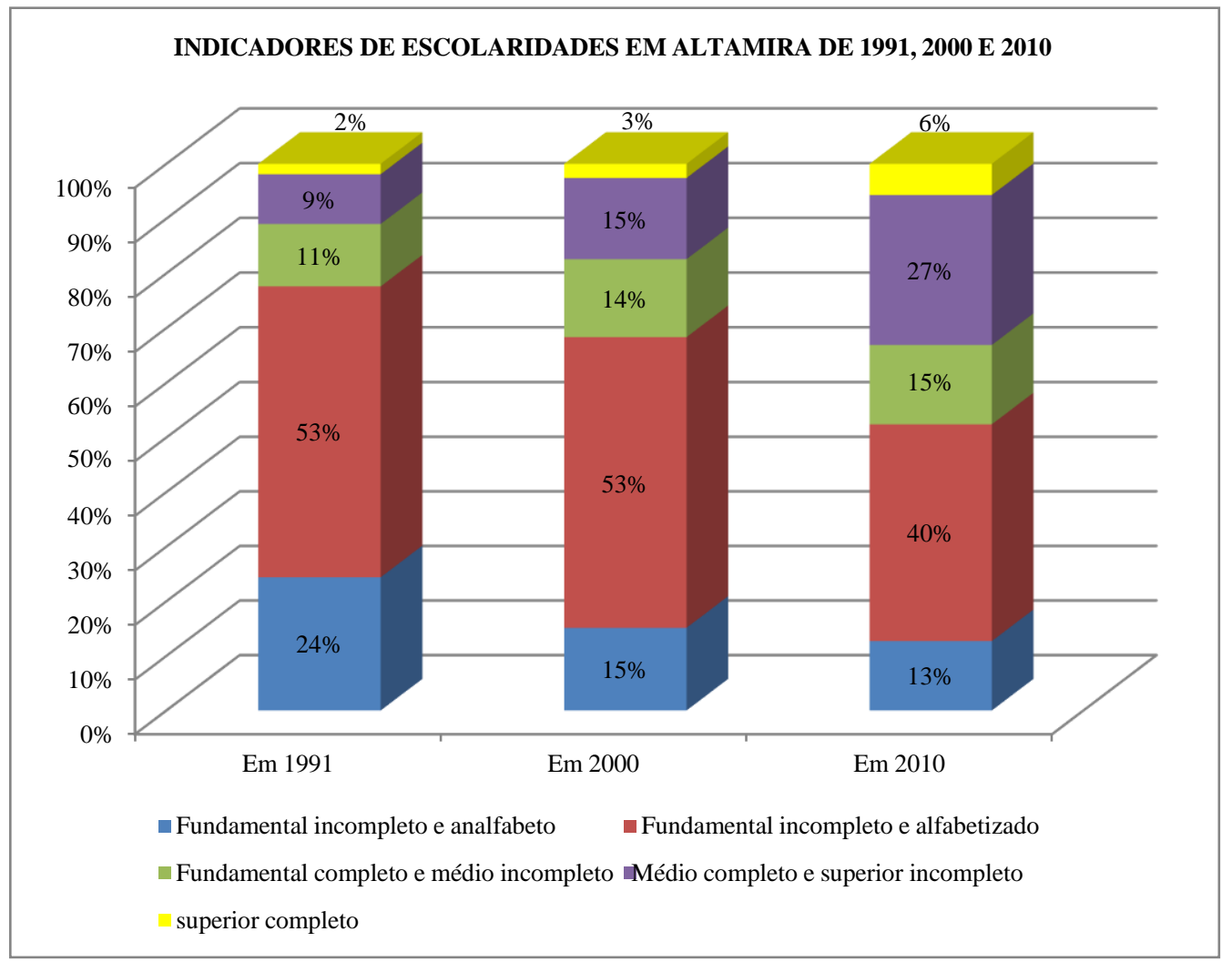

Fonte: Atlas Brasil 2013 (extraído pelos autores).

Altamira apresenta semelhanças em seus índices de escolaridade com Tucuruí no mesmo período, destaca-se a diferença nas taxas de pessoas com ensino "médio completo e superior incompleto", que passou de 11\% em 1991para 14\% em 2000, um crescimento de $3 \%$, e no interregno dos 10 anos seguintes chegou a $27 \%$ de escolaridade nessa faixa. Ou seja, em 19 anos (1991 a 2010) teve um crescimento de 16\%. A taxa de pessoas com

\begin{tabular}{|l|l|l|l|}
\hline \multicolumn{1}{|c|}{ ISSN 2596-1314 } \\
CAMPOS NEUTRAIS & Rio Grande & v. 3, n. 2 & p. 31-51 \\
REVISTA LATINO-AMERICANA DE RELAÇÕES INTERNACIONAIS & Maio-Ago 2021 \\
\hline
\end{tabular}


Os desafios socioambientais da construção de hidrelétricas na Amazônia: os casos dos municípios de Tucuruí e Altamira no estado do Pará

Dolores Silva et al.

fundamental incompleto e analfabetas caiu cerca de $50 \%$ no período analisado. Em ambos os municípios quase metade da população (40\%) é analfabeta e semianalfabeta.

\subsection{Desenvolvimento humano nas cidades de Tucuruí e Altamira e condições socioambientais.}

Avaliar o Índices de Desenvolvimento Humano Municipal (IDHM) ${ }^{11}$ é importante para nosso estudo, uma vez que os munícipios estudados tiveram sensível alteração na qualidade de vida ao longo do tempo. Esse índice considera os indicadores de longevidade, educação e a renda da população.

Tucuruí registrou 0,666 de IDHM em 2010, o que situa esse município na faixa de desenvolvimento humano médio (intervalo de 0,600 a 0,699). A dimensão que mais contribuiu para o IDHM do município foi a longevidade, com índice de 0,800, seguida de renda, com índice de 0,675 e de educação, com índice de $0,548^{12}$.

Tabela 4. Índice de Desenvolvimento Humano Municipal dos Municípios

\begin{tabular}{ccc}
\hline Ano & Tucuruí & Altamira \\
\hline $\mathbf{1 9 9 1}$ & 0,421 & 0,386 \\
$\mathbf{2 0 0 0}$ & 0,543 & 0,534 \\
$\mathbf{2 0 1 0}$ & 0,666 & 0,665 \\
\hline
\end{tabular}

Fonte: IBGE (Produção dos próprios autores).

Altamira registrou IDHM de 0,665 em 2010, apresentando também um IDHM médio. A dimensão que mais contribuiu para o IDHM do município em questão foi a longevidade, com índice de 0,811 , seguida de renda, com índice de 0,662 e educação, com índice de $0,548^{13}$. Os dois municípios tem índices semelhantes, sendo a longevidade fator preponderante para que Altamira e Tucuruí figurem dentro da média nacional.

Outros dados interessantes a serem observados referem-se a saneamento e arborização dos municípios, no caso de Altamira apenas 17,8\% de todos os domicílios urbanos apresentam esgotamento sanitário, desse percentual menos da metade $(44,3 \%)$ são esgotamentos adequados. Nos domicílios urbanos apenas $22,7 \%$ possuem arborização. Com $77 \%$ de domicílios urbanos sem arborização e $82 \%$ sem esgotamento sanitário fica evidente as péssimas condições ambientais desse município.

\footnotetext{
${ }^{11} \mathrm{O}$ IDMH é um índice que varia de 0 a 1, quanto mais próximo de 1 , maior o desenvolvimento humano.

${ }^{12}$ http://www.atlasbrasil.org.br/2013/pt/perfil_m/tucurui_pa

${ }^{13}$ http://www.atlasbrasil.org.br/2013/pt/perfil_m/altamira_pa\#idh\#idh
} 


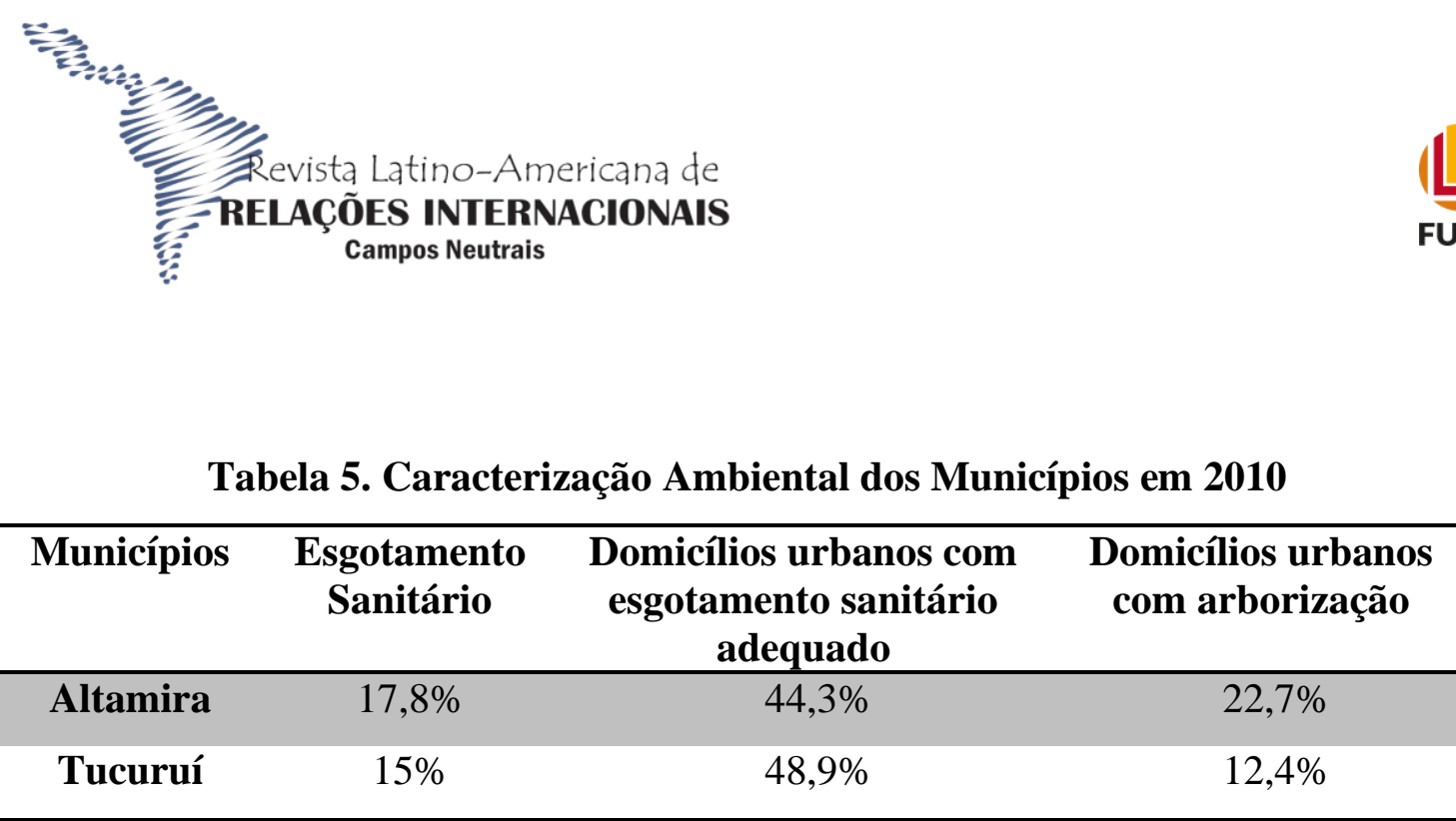

Fonte: IBGE

Para o município de Tucuruí os índices são ainda piores, somente 15\% dos domicílios possui esgotamento sanitário, desses menos da metade (48,9\%) são adequados. Quanto aos domicílios com arborização apenas 12,4\% tem essa caracterização. Os 87,6\% de domicílios sem arborização e $85 \%$ sem nenhum esgotamento sanitário, mostram que os projetos de desenvolvimento que são instalados nos municípios não foram acompanhados de boa qualidade de vida para população.

A antecedência no tempo da instalação da UHT não deixa dúvida de que o desenvolvimento almejado pelos grandes projetos enfrenta o paradoxo de deixar um rastro de problemas sociais e ambientais para a população local. Essas condições de vida precárias do meio urbano são agravadas pelas queimadas e o desmatamento no meio rural. Esse cenário já era esperado por setores da sociedade civil que acompanham a instalação de grandes projetos econômicos e de infraestrutura na Amazônia. Como destaca Pereira (2014, p.19), a respeito da UHBM:

"Por outro lado, a implementação de uma grande usina hidrelétrica em uma região com forte presença de populações indígenas, de Unidades de Conservação (UC) e com grande biodiversidade alertou ambientalistas - nacionais e internacionais, grupos indígenas, organizações de direitos humanos, entre outros para os severos impactos de BM. Além disso, havia um grande medo de que as promessas de dinamização da economia e de melhoria de infraestrutura na região do Xingu teriam efeitos inversos, já que a atração de um grande contingente populacional sobrecarregaria a estrutura de serviços básicos - como os da área de saúde e de educação - da região, que já eram insuficientes para a própria população local". 
Os desafios socioambientais da construção de hidrelétricas na Amazônia: os casos dos municípios de Tucuruí e Altamira no estado do Pará

Dolores Silva et al.

As contestações do ministério Público no caso da usina de Belo Monte, a respeito de medidas compensatórias não cumpridas satisfatoriamente pela empresa Norte energia, e os protestos de grupos sociais e movimentos organizados refletem as experiências com grandes empreendimentos anteriores, como o caso da usina hidrelétrica de Tucuruí. A população não tem suas reivindicações atendidas e sofre com a alteração de suas condições de vida, tanto nas cidades quanto no meio rural (SEQUEIRA, 2014, p. 77-79). Em outro contexto amazônico, Vasconcelos (2018) analisou as ações judiciais relativas às hidrelétricas do Rio Madeira, no estado de Rondônia, e constatou que as decisões são mais lentas e desfavoráveis quando respondem às reivindicações de grupos sociais locais impactados.

Resolver o paradoxo dos projetos voltados ao desenvolvimento na Amazônia, que extrai recursos naturais, produz imensas riquezas e não transforma positivamente as condições de vida das populações locais é um desafio ainda em aberto na historia das políticas de desenvolvimento regional.

\section{Considerações Finais}

Vimos que a história de Tucuruí é diferente do ponto de vista do processo decisório da construção da UHT em contexto autoritário em que ainda não era forte a atenção pública brasileira para os problemas ambientais. A distância no tempo na efetivação dos projetos dos dois casos analisados nos possibilita refletir sobre a chegada do propagado progresso nessas regiões que sofrem impacto de grandes projetos de desenvolvimento econômico. Tucuruí e Altamira tem IDHM semelhante, a despeito da segunda, apresenta problemas socioambientais mais agudos em virtude de ser mais recente a atração populacional para seu território. Mas, depois de quase 40 anos da inauguração da hidrelétrica de Tucuruí as populações tradicionais ainda cobram compensações pelos danos ao seu modos de subsistência, assim como, também, no meio urbano não se apresentam índices de qualidade de vida positivos significativos.

Apesar da maior participação social no caso Belo Monte, institucionalizada a partir dos fundamentos constitucionais da Constituição de 1988, são grandes os problemas socioambientais que se aprofundam e que parecem não ter solução no sentido de melhorar a vida da população. A redução do escopo do projeto para minorar os impactos ambientais na região do Xingu (PA) não torna menor o drama daqueles que são impactados, e isso inclui tanto a população urbana que cresceu em função do projeto, quanto as populações 


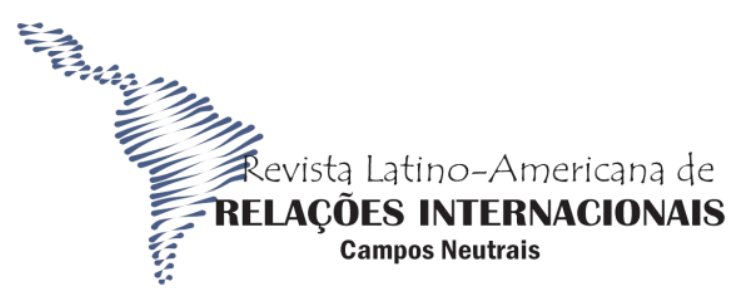

FURG

tradicionais que vivem na zona rural, como os índios, quilombolas e ribeirinhos. Não tratamos destes grupos sociais no escopo deste artigo, pois exigiriam dados mais detalhados, mas são fartos os diagnósticos a respeito do descontentamento desses contingentes populacionais.

A despeito dos índices de desenvolvimento humano municipal dos dois municípios estarem na média nacional, a média salarial de grande parte da população é de meio salário mínimo, o nível de educação é baixo, o saneamento e a arborização dos municípios é incipiente e a taxa de homicídios é alta. Merecem estudos comparativos mais aprofundados o fato de que cidades paraenses que não têm grandes projetos instalados em seus territórios possuem índices de violência, desemprego e analfabetismo menores.

Recuperando Draibe e Riesco (2011), quando caracterizam o Estado Latino Americano Desenvolvimentista de Bem Estar (ELADBE), temos que ter como referencia uma concepção de desenvolvimento onde a preocupação com o bem estar da população deve ser referencia para a intervenção do Estado. Vimos nos casos que analisamos, que no exemplo de dois grandes projetos de infraestrutura para a produção de energia, a UHT e a UHBM no estado do Pará, grandes problemas socioambientais se instalam e se aprofundam no contexto local. Os impactos sobre a biodiversidade sequer foram tratados nesta breve reflexão, pois merecem abordagem em um escopo compatível com sua complexidade.

\section{Referências}

ALONSO, A. et al . Identidade e Estratégia na Formação do Movimento Ambientalista Brasileiro. Novos Estudos CEBRAP, vol. 79, p. 151-167, 2018.

CARDOSO, F.H.; MÜLLER, G. Amazônia: expansão do capitalismo [online]. Rio de Janeiro: Centro Edelstein de Pesquisas 2008. http://www.fgv.br/cpdoc/acervo/arquivos/DHBBBiblioGeral.pdf

\begin{tabular}{|l|l|l|l|}
\hline \multicolumn{1}{|c|}{ ISSN 2596-1314 } \\
CAMPOS NEUTRAIS & Rio Grande & v. 3, n. 2 & p. 31-51 \\
REVISTA LATINO-AMERICANA DE RELAÇÕES INTERNACIONAIS & Maio-Ago 2021 \\
\hline
\end{tabular}


Os desafios socioambientais da construção de hidrelétricas na Amazônia: os casos dos municípios de Tucuruí e Altamira no estado do Pará

Dolores Silva et al.

CASTRO, Edna. Produção de conhecimento sobre hidroelétricas na área de Ciências Humanas no Brasil. Revista Novos Cadernos NAEA, vol.21, n3, p. 31-59, 2018.

DRAIBE, Sonia; RIESCO, Manuel. Estados de Bem-Estar Social e estratégias de desenvolvimento na América Latina. Um novo desenvolvimentismo em gestação?. Sociologias, Porto Alegre, ano 13, nº 27, 2011. p. 220-254.

EVANS, Peter. "The state as problem and solution: predation, embedded autonomy and structural change". In HAGGART, Stephan; KAUFRNAN, Robert (cds.). Politics of Economic Adjustment Princeton University Press, 1992. Tradução de Cid Knipel Moreira. FERREIRA, Sylvio M. P.; BASTOS, Pedro P. Z. As origens da Política Brasileira de Desenvolvimento Regional: $O$ caso da Superintendência da Valorização Econômica da Amazônia (SPVEA). Texto para discussão (266). Instituto de Economia da UNICAMP, 2016. Recuperado de https://www.eco.unicamp.br/images/arquivos/artigos/3461/TD266.pdf]

LIRA, S. B. Morte e ressureição da SUDAM. Uma análise da decadência e extinção do padrão de planejamento regional na Amazônia. Belém: NAEA-UFPA, 2005.

PEREIRA, Ana Karine. Desenvolvimentismo, conflito e conciliação de interesses na política de construção de hidrelétricas na Amazônia brasileira. In: GOMIDE A. A.; PIRES, R. R. C. (Org.). Capacidades estatais e democracia: arranjos institucionais de políticas públicas. Brasília: Ipea, 2014. pp. 161-185.

PINTO, Lúcio Flávio. Hidrelétrica: A última inauguração. Revista Jornal Pessoal: A agenda Amazônica. Ano. XXXIII, nº63, 2019.

PRATES, Daniela M.; FRITZ, B.; PAULA, L. F. Uma avaliação das políticas desenvolvimentistas nos governos do PT. Cadernos do Desenvolvimento, Rio de Janeiro, vol. 12 , n. 21,2017 . p. 187-215.

SEQUEIRA, João Élbio O. A. A rede de ativismo transnacional contra a construção da Usina Hidrelétrica de Belo Monte. Dissertação (Mestrado em Ciência Política). Universidade Federal do Pará, Belém, 2014. Recuperado de http://ppgcp.propesp.ufpa.br/ARQUIVOS/dissertacoes/

SEQUEIRA, João Élbio; SILVA, Maria Dolores. O ativismo judicial transnacional e a “Transnational Advocacy Network” na construção da Usina Hidrelétrica de Belo Monte. 


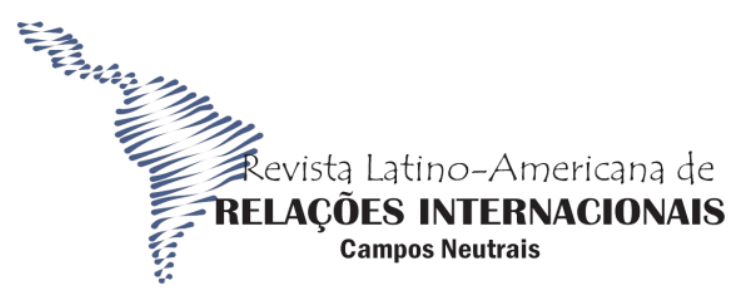

FURG

Revista Política Hoje, vol. 23, $\mathrm{n}^{\mathrm{o}} 1$, pp. 177-201, 2015. Recuperado de [https://periodicos.ufpe.br/revistas/politicahoje/article/view/3747 ]

SERRA, Maurício Aguiar; FERNÁNDEZ, Ramón G. Perspectivas de desenvolvimento da Amazônia: motivos para o otimismo e para o pessimismo. Economia e Sociedade, Campinas, v. 13, n. 2 (23), p. 107-131, 2004.

SILVA, Maria Dolores L. A Amazônia e o desenvolvimento: aspectos da trajetória das políticas públicas na região. REB-Revista de Estudios Brasileños, vol. 7, n 15, pp. 219 232, 2020. Recuperado de [ https://gredos.usal.es/bitstream/handle/10366/145697 ]

SILVA, Maria Dolores; CABRAL, Eugênia R. Produção de legislação ambiental em dois contextos institucionais. O Social em Questão, ano XXI, nº 4, 2018. Recuperado de [http://osocialemquestao.ser.puc-rio.br/media/osq_40_art_3 ]

SILVA, Maria Dolores L.; ROSA, Benilde N. L. Socioambientalismo e políticas públicas em perspectiva as RESEXs na Amazônia paraense. Conexões, vol. 6, nº 1, pp. 171-197, 2013.

TRINDADE, José $\quad$ R. B. Seis décadas de intervenção estatal na Amazônia: a SPVEA, auge e crise do ciclo ideológico do desenvolvimentismo brasileiro. Belém: Paca-Tatu, 2014.

VASCONCELOS, Patrícia M. C. Hidrelétricas do Madeira e o acesso à justiça. Quaestio Iuris, vol. 11, $\mathrm{n}^{\mathrm{o}}$ 4, pp. 3049-3068, 2018. Recuperado de [https://www.epublicacoes.uerj.br/index.php/quaestioiuris/article/view/38053/27080] 